\title{
Rapid Urbanization as a Source of Social and Ecological Decay: A Case of Multan City, Pakistan
}

\author{
Ghulam Yasin (Corresponding author) \\ Assistant Professor, Department of Sociology \\ Bahauddin Zakariya University, Multan, Pakistan \\ Tel: 92-61-921-0448 E-mail: miannyasin@yahoo.com
}

Sumaira Sattar

Department of Sociology, Bahauddin Zakariya University, Multan, Pakistan

Farhan Ahmad Faiz

Lecturer, Department of Sociology

Bahauddin Zakariya University, Multan, Pakistan

Received: November 17, 2011

Accepted: December 12, 2011 Published: April 1, 2012

doi:10.5539/ass.v8n4p180

URL: http://dx.doi.org/10.5539/ass.v8n4p180

\begin{abstract}
This paper concentrates on the relationship between rapid urbanization and socio-ecological problems. The major objective of this study is to analyze the unplanned and haphazard urbanization that is giving birth to environmental issues such as; pollution, poor drainage system, poor quality of drinking water and poor hygienic conditions. This research carried out in Multan city, Pakistan through field survey of 200 respondents using multistage sampling technique. Self-administrated questionnaire was used as a tool of data collection and the binary logistic regression was employed for the analysis of the data. The results depict that urbanization is one of the major causes of converging joint family system to the nuclear family system and its changing function as a consequence. It is also a source of reduction of greenery and trees in the city. It is causing problem of poor sanitation system and quality of drinking water. Pollution is another outcome of haphazard and unplanned urbanization. The researcher also found that due to migration from rural to urban areas, the life in the city implicates adversely the quality of life. This study provides better insight on the problems of urbanization in urban areas and will also help policy makers to focus on major areas of improvement such as to check the migration from rural to urban. To enforce the urban laws to reduce the problems of sanitation, check on transport system, quality of drinking water, domestic and industrial waste. The researcher suggests the monitoring of the migration from rural to urban areas through provision of basic facilities in rural areas. On the other hand awareness campaigns and provision of basic facilities to the rural people (educational facilities, health facilities, food and empowerment in basic decision making) can reduce this problem.
\end{abstract}

Keywords: Urbanization, Social and ecological decay, Pollution, Water, Pakistan

\section{Introduction}

Urbanization and urban glide is the physical escalation of urban areas. Resultantly changes come in the urban areas that may be poverty, environmental degradation and poor quality of life. Urbanization is one of the serious global problems. As the development takes place from agricultural to an industrial sector, large scale urbanization takes place. During this process the growth rate of urban areas is typically double the pace of overall population increase. Some 29 percent of the world population was living in urban areas in 1950; this figure was 43 percent in 1990, and the estimated figure for the year 2030 is about 61 percent (Manzoor, M. et al., 2010).

History of urbanization in Pakistan can be divided into four phases in which both the in and out migration have occurred. The first phase of urbanization starts with the partition of British Indian Empire, when more than six 
million people migrated towards newborn country. Majority of them settled in Pakistan. Second phase started in the mid 1950s the government starts the process of industrialization. The opportunities of good life and employment encouraged million of the rural people migrate to cities. The third phase started with the breakup of East Pakistan in 1971. All the supporters of Pakistan in Bangladesh were forced to leave the country. The fourth but very complex and serious phases in 1980s, at this times changing in the neighboring countries, such as Iran and Afghanistan greatly added to already continuing process of urbanization in Pakistan. History of urbanization in Pakistan shows that the process of urbanization has remained continuous and ongoing phenomena and each decade has added something in it. Unusual growth of a few large cities is another aspect of Pakistan's urbanization. The city of Karachi alone contributes $21.7 \%$ to the total urban population of Pakistan, while the city of Lahore contributes 12.7 percent. They along with the biggest seven cities including Faisalabad, Rawalpendi, Multan, Hyderabad, Gujranwala, Peshawar and Quetta contain 54.6 percent of Pakistan urban population (Pakistan Education Cell, 2001).

The recent patterns and trends of urban growth in developing countries, over the last 20 years many urban areas have experienced dramatic growth, as a result of rapid population growth and as the world's economy have been transformed by a combination of rapid technological and political change. Around 3 billion people virtually half of the world's total population-now live in urban settlements. And while cities command an increasingly dominant role in the global economy as centers of both production and consumption, rapid urban growth throughout the developing world is seriously outstripping the capacity of most cities to provide adequate services for their citizens. Over the next 30 years, virtually all of the world's population growth is expected to be concentrated in urban areas in the developing world. While much of the current sustainable cities debate focuses on the fearsome problems for the world's largest urban agglomerations, the majority of all urban dwellers continue to reside in far smaller urban settlements. Many international agencies have yet to adequately recognize either the anticipated rapid growth of small and medium cities or the deteriorating living conditions of the urban poor (Cohen, 2005). The Urbanization is one of the most important demographic trends of the twenty-first century, and growth is particularly rapid in lower-income countries. The majority of urban growth is associated with the rapid expansion of smaller urban centers and peri-urban developments. Much of this growth is unplanned and informal, with community members and informal-sector developers taking advantage of the fact that the regulatory capacity of government authorities is weak, particularly in those areas that are outside official municipal boundaries (Parkinson and Tayler 2003).

To understand the critical linkages between urbanization, public health and habitat, the environment, population growth, and international security, Ellen (1999) highlights the trends in urban growth, particularly in the developing world, and their potential to affect the international community. Issues addressed include migration to urban centers, the immediate environmental and health impacts of urban pollution on developing country cities, and the link between crime and security. Urbanization does not have only local environmental impacts but also large so-called 'ecological footprints' beyond their immediate vicinity. Intensive and extensive exploitation of natural resources to support urban economy includes excessive extraction of energy resources (including fuel wood), quarrying and excavation of sand, gravel and building materials at large scales, and over extraction of water. These all contribute to degradation of the natural support systems and irreversible loss of critical ecosystem functions, such as the hydrological cycle, carbon cycle and biological diversity, in addition to conflicts with rural uses of such limited resources. Other effects can be felt further a field such as pollution of waterways, long-range air pollution that impact on human health as well as on vegetation and soils at a considerable distance (Henderson, 2006).

\subsection{Purpose of the study}

We are living in the era of post modernity where the rapid development and the changes come in fast speed. People try to get more facilities and to adopt new technology to bring comfort in their lives. To get these facilities they move to cities where they think they can earn more and able to avail these facilities, thus urbanization takes place. Situation becomes worst when haphazard pressure of population starts pressing and increasing burden on cities in manifolds. Pakistan being an under developed country has been facing the same problem since its birth and later divide. Multifaceted problems are being encountered by urban dwellers. High population growth and migration from rural to urban centers are constantly promoting this issue. An extensive research work has been done on this issue in the context of developed world. But studies related to developing countries like Pakistan do not provide sufficient literature to properly analyze the relationship between rapid urbanization and socio-ecological problems. In this research the researcher's aim to study major social and environmental problems due to urbanization and addresses the following research questions.

1) What are the effects of urbanization on the overall living conditions of urban dwellers? 
2) Problems of drainage system in urban areas.

3) Conditions of drinking water.

4) Urbanization a source of increasing pollution.

5) How urbanization affects hygienic condition of the people living in urban areas.

6) To suggest some suitable measure to reduce the affects of urbanization.

\section{Review of literature}

Vlahov and Galea (2002) estimated that a majority of the world's population will live in urban areas by 2007. The most rapidly urbanizing cities are in less-wealthy nations, and the pace of growth varies among regions. There are few data linking features of cities to the health of populations. They suggest a framework to guide inquiry into features of the urban environment that affect health and well-being. They consider two key dimensions: urbanization and urbanicity. Urbanization refers to change in size, density, and heterogeneity of cities and the Urbanicity refers to the impact of living in urban areas at a given time. They suggest that most of the important factors that affect health can be considered within three broad themes: the social environment, the physical environment, and access to health and social services. The development of urban health as a discipline will need to draw on the strengths of diverse academic areas of study (e.g., ecology, epidemiology, sociology). Cross-national research may provide insights about the key features of cities and how urbanization influences population health.

Cohen (2006) provides a broad overview of the recent patterns and trends of urban growth in developing countries. He said over the last 20 years many urban areas have experienced dramatic growth, as a result of rapid population growth and as the world's economy have been transformed by a combination of rapid technological and political change. And while cities command an increasingly dominant role in the global economy as centers of both production and consumption, rapid urban growth throughout the developing world is seriously outstripping the capacity of most cities to provide adequate services for their citizens. Many international agencies have yet to adequately recognize either the anticipated rapid growth of small and medium cities or the deteriorating living conditions of the urban poor. In an increasingly urban world, almost half the world's total population and over three quarters of the population of high-income countries now live in urban areas. Rural-urban migration and the transformation of rural settlements into towns and cities have been important determinants of rapid urban growth but there has also been a general convergence in lifestyles between urban and rural areas as advances in transportation and telecommunication have caused distance and time to collapse.

Antharvedi (2007) discusses in his article about the Ecological Sustainable Development and explains the factors that lead to the ecological degradation in the context of Urbanization. Population growth is the key factor for the environmental urban pollution. Rapid urbanization is taking place at the cost of the ecology causing noise pollution, air pollution etc. Urban transportation is also the major factor for the environment pollution. The implications of sustainable development can be effectively addressed only through international cooperation in developing, accessing and diffusing appropriate knowledge and technology, especially for developing countries. By improving human settlement, creating environmental awareness in the citizens, implementation of integrated planning and management we can improve the sustainability of the environment. International co-operation to develop appropriate technologies for sustainable development should start with the identification of local needs. The precautionary approach is to be applied by states according to their capabilities for the substantiating the environment for the present and the future generations.

Taha, S. M. (2010) presented trends in the population growth and urbanization in Lahore with the growth in the air pollution, water pollution and change in the forestation recourses in Lahore district. The main purpose is to bring all these different issues together and find out whether our environmental resources (clean drinking water, clean air and trees) in Lahore are decreasing, increasing, or staying at a constant level. The rapid urbanization is accompanied by environmental problems such as pollution, waste management, congestion and imbalance in fragile ecosystem. Air pollution has always been a problem in Lahore. About 2 percent of total deaths are attributed to air pollution in Lahore. According to this report 22,700 people die because of increase in urban air pollution. This inferior air quality in Lahore is the effect of vehicular and industrial emissions. The industries which were setup far from Lahore now come under Lahore because the population is expanding. Clean drinking water is scarce in Lahore. Most of the population in Lahore never drinks clean water. Water contamination is mainly caused by the poor sewerage systems at different parts of Lahore.

Lindh (1983) concluded that the provision of water supply, sanitation and drainage are vital elements of the urbanization process. Major differences exist between higher-income areas, where the process is planned in 
advance, and low-income areas of developing nations, where informal settlements are progressively consolidated into urban areas. Sanitation and drainage arrangements are fundamental to consideration of the urban hydrological cycle.

Cronin et al. (2004) argued that the Groundwater is a vital source of drinking water in African towns and cities, but this resource often has been compromised by the combined use of aquifers as a repository for human waste. Previous research has generally focused on microbiological contamination from on-site sanitation in African towns. However, degradation of chemical water quality by industrial wastage can also impact on health, especially as a result of nitrate contamination associated with on-site sanitation. This has often been neglected in past studies of water quality in urban areas.

Bruce et al., (2000) concluded that the indoor air pollution in the developing world is most often associated with the use of biomass fuels coal, wood, animal dung, and kerosene, although indoor tobacco smoke is also an increasing contributor. Indoor air pollution affects both rural and urban populations.

Moorea et al., (2003) found that nearly half the world's population now lives in urban settlements. Cities offer the lure of better employment, education, health care, and culture; and they contribute disproportionately to national economies. However, rapid and often unplanned urban growth is often associated with poverty, environmental degradation and population demands that outstrip service capacity. These conditions place human health at risk. Reliable urban health statistics are largely unavailable throughout the world. Disaggregated intra-urban health data, i.e., for different areas within a city, are even rarer. Data that are available indicate a range of urban health hazards and associated health risks: substandard housing, crowding, air pollution, insufficient or contaminated drinking water, inadequate sanitation and solid waste disposal services, vector-borne diseases, industrial waste, increased motor vehicle traffic, stress associated with poverty and unemployment, among others. Local and national governments and multilateral organizations are all grappling with the challenges of urbanization. Urban health risks and concerns involve many different sectors, including health, environment, housing, energy, transportation, urban planning, and others.

World Development Report (1999/2000) analyzed that Rapid and often unplanned, urban growth is the source for many of the environmental hazards faced by cities within the developing world. Substandard housing on marginal land, crowding, increasing levels of air pollution, water pollution and over usage, inadequate sanitation services, inadequate solid waste collection, and motor vehicle traffic and traffic injuries are all associated with rapid growth of urban centers.

Lee and Fujita (1997) have created an economic model to determine whether alternative locations of greenbelts that may define urban growth boundaries and are characterized by the level of service they provide are efficient. They found that when the greenbelt is a pure public good the only optimal location is outside the urban fringe. However, when the greenbelt is an impure public good then, under certain reasonable assumptions about utility, income, and type of service, it may be optimal to locate the greenbelt inside the urban area.

\section{Methods}

The researcher used quantitative research design to evaluate the different aspects of ecological and social decay as a result of rapid urbanization. The data was collected from Multan city (universe) through multistage sampling technique. The researcher selected Mumtazabad town out of six towns (Shah-Rukn-e-Alam town, Sher Shah town, Mumtazabad town, Bosan town, Shujaabad town and Jalal Pur Pirwala town) through simple random sampling technique in the first stage of sample selection. Subsequently the researcher selected $n=3$ colonies (Bilal colony, Walatabad colony and Nazarabad colony) out of $\mathrm{N}=24$ colonies through purposive sampling technique (The major purpose was that the selected areas must be suffered from excessive social and ecological decay due to rapid urbanization) in second stage of sample selection. The researcher interviewed 200 respondents $(\mathrm{n} 1=120$ males and $\mathrm{n} 2=80$ females) through convenient sampling technique. The researcher used interview schedule to evaluate the responses regarding different aspects of rapid urbanization like urban health hazards, substandard housing, crowding, air pollution, insufficient or contaminated drinking water, inadequate sanitation and solid waste disposal services, water-borne diseases, industrial waste, stress associated with poverty and unemployment, among others. The data was collected through self administered questionnaire to evaluate the responses of the urban dwellers. The researcher selected the respondents on the specific criterion of minimum literacy rate up to intermediate level in order to maximize the response rate. Both structured and unstructured questions were used in the questionnaire to appraise the responses of the urban dwellers. Structured questions were used to measure the responses on the basis of predetermined scale. Over and above unstructured questions facilitated the researcher to gain a deep insight about different aspects of the conducted research. Then the researcher coded the data using SPSS (version 17). The researcher divided the detailed information into 
number of categories that enabled simple description of the data for various statistical purposes. These categories comprised of demographic characteristics, social and ecological decay in urban areas as well as its implications on overall living conditions of urban dwellers. A number of hypotheses constructed in the light of beforehand conducted researches were tested on the basis of empirical authentications taken from data. Binary logistic regression test was applied to test hypothesis. As the response categories of the respondents were present in binomial form therefore the researcher used this statistical test to maximize the accuracy of the given data.

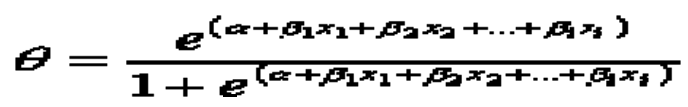

Where $\alpha=$ the constant of the equation and,

$\beta=$ the coefficient of the predictor variables.

\subsection{Limitations of the Study}

Due to minimum research funds, this study confines to Multan city which houses a significant number of migrated population of the southern punjab due to manifold reasons but ultimately it turns up in providing a nest to various ecological challenges. Moreover, a careful sample size was taken to maximum generalize this issue to the urban problems, however if the sample size increases this issue can be studied in more adequate manner. This study further invites the attention of researchers and policy makers alike for further bench marks to help establish the key intrinsic variables behind the phenomenon.

\section{Empirical Results and Discussion}

\subsection{Demographics}

In the survey of 200 respondents, $78.5 \%$ belong to the age category of $18-29$ years. Pakistan Social and Living Standards Measurement Survey (2010-11) found similar results that majority of the population in Pakistan consisted on the young people. Majority $60 \%$ were male while the female were $40 \%$. Majority $66 \%$ belonged to the nuclear family set up while $34 \%$ were from the joint family set-up. Furthermore $58 \%$ respondents were migrants and $42 \%$ respondents were non-migrants. Brennan (1999) added to the finding that between 1950 and 1975, 32 million new urban dwellers were added annually worldwide about two-thirds in the developing countries. Currently, 59 million new urban dwellers are added annually 89 percent in developing countries. By 2025-2030, 76 million will be added annually 98 percent in developing countries.

\section{Hypothesis No. 1: Rapid urbanization growth is the leading cause of ecological decay in the cities.}

Keeping in view the model specification and testing of hypothesis, the results from the regression analysis revealed the majority $68 \%$ were of the view that with the growth of urbanization the greenery decrease in the cities, while $32 \%$ were not agreed. The p-value in the Table No.1 indicates that urbanization reduces greenery and trees. Due to rapid urbanization the cultivated areas are drastically converted into residential areas because each year thousands of people are migrating to urban areas and more land is needed for residence, so trees and greenery are decreasing day by day and causing ecological decay which results in increasing pollution and other environmental issues. These results are similar what Martinez, et al. (2002) has found.

$<$ Insert Table 1 Here $>$

\section{Hypothesis No. 2: Rapid urbanization is the major determinant of increased nuclear family construction.}

Empirical evidence found from the data analysis depicts that the majority of the respondents $66 \%$ were of the view that urbanization is giving birth to the conversion of joint family set-up to the nuclear family set-up. There exists an association between urbanization and change in family system. The Table No. 2 shows the results of binary logistic regression that higher the rate of urbanization greater will be the change from joint to nuclear family. The p-value in the table indicates that there is a significant effect of urbanization on family system so urbanization is the main contributing factor for reducing joint family system and increase in individualism in the society that leads to nuclear family system. Bengtson (2001) has opined that nuclear family is changing its imperative role as the consequence of urbanization wherein with the increase in urbanization, individualism and secularism increases, and the emancipation of women in the resultant factor. This transition proposes that the modal structure of families had changed from extended to nuclear, and its primary functions have evolved from social-institutional to emotional-supportive.

$<$ Insert Table 2 Here>

Hypothesis No. 3: Urbanization results in poor sanitation facilities in the urban areas. 
The study revealed that the majority of the respondents $66 \%$ opined in affirmative that increase in urbanization is the major cause of affected sanitation system, while $34 \%$ disagreed with the proposition. So the result of binary logistic regression shows that there is an association between urbanization and poor sanitation facilities in the urban areas. The p-value in the table indicates that urbanization has significant effect on sanitation facilities. So increasing urbanization is the main contributing factors for affected sanitation system in the urban areas that affect the human health adversely. The result is the rapid prevalence of epidemics among the urban dwellers. Among the diseases resulting from poor sanitation, unclean water and poor waste disposal are dysentery, cholera, typhus fever, typhoid and trachoma. These results are similar what has Geoforum and Zoulani (2007) estimated that at least two billion people have inadequate sanitation. By virtue of its cost and water requirements, he further argues that conventional sewerage is an implicitly anti-poor technology. Therefore, simplified sewerage is often the only sanitation technology that is technically feasible and economically appropriate for low income, high-density urban areas.

$<$ Insert Table 3 Here>

\section{Hypothesis No. 4: Urbanization affects the quality of drinking water.}

The analysis of binary logistic regression on whether the quality of drinking water is to the association while $40 \%$ responded in the other way round. The p-value indicates that there is significant effect of urbanization on water quality. Water contamination is mainly caused by the poor sewerage system at different parts of urban areas mainly because of the disposal of waste from the industries being mixed with the water supply lines. These results are similar what has Cronin et al. (2004) found that groundwater is a vital source of drinking water in African towns and cities, but this resource often has been compromised by the combined use of aquifers as a repository for human waste. Moreover, degradation of chemical water quality can also impact on health, especially as a result of nitrate contamination associated with on-site sanitation.

$<$ Insert Table 4 Here $>$

\section{Hypothesis No. 5: Higher urbanization leads towards increased air pollution in cities.}

The binary logistic regression analysis on higher the rate of migration from rural to urban areas will be, the greater the air pollution in cities. Empirical evidence depicts that the significant majority of the respondents $71.5 \%$ agreed to the analogy that migration from rural to urban areas increase the air pollution in the cities, while $28.5 \%$ disagreed. The p-value in the table indicates that urbanization has significant effect on increasing air pollution. By urbanization air pollution is increasing in the developing world thus inviting the attention of epidemiologists to address the spread of epidemics resulting from the air pollution. Asthma, chronic obstructive pulmonary disease, lead and beryllium poisoning are associated with increasing air pollution. These results are similar what has Brennan (1999) been found that there is a critical linkages between urbanization, the environment, population growth and pollution.

$<$ Insert Table 5 Here $>$

\section{Summary and Conclusion}

This paper investigates the relationship between rapid urbanization and socio-ecological problems keeping in view the basic human rights of access to safe and healthy environment, which is being compromised due to unplanned migratory flows of human population from rural to urban areas. The major objective of this study is to analyze the unplanned and haphazard urbanization that is giving birth to environmental issues such as; pollution, poor drainage system, poor quality of drinking water and poor hygienic conditions. This research was carried out in Multan city, Pakistan through field survey of 200 respondents using multistage sampling technique. Self-administrated questionnaire was used as a tool of data collection and the binary logistic regression was employed for the analysis of the data.

The hypotheses formulated for the present study were;

a) Rapid growth of urbanization is causing ecological decay in the cities.

b) Rapid urbanization is the major determinant of increased nuclear family construction.

c) Urbanization results in poor sanitation facilities in the urban areas.

d) Urbanization affects the quality of drinking water.

e) Higher urbanization leads towards increased air pollution in cities.

The results depict that urbanization is one of the major causes of converging joint family system to the nuclear family system and its changing function as a consequence. It is also a source of reduction of greenery and trees 
in the city. It is causing problem of poor sanitation system and quality of drinking water. Pollution is another outcome of haphazard and unplanned urbanization. The study revealed that the rapid urbanization is creating environmental issues in the urban areas such as air pollution, poor water quality, Sanitation and waste water treatment, Increase the temperature of Earth, increasing slums areas etc. The researcher also found that due to migration from rural to urban areas, the life in the city implicates adversely the quality of life. This study provides better insight on the problems of urbanization in urban areas and will also help policy makers to focus on major areas of improvement such as to check the migration from rural to urban.

\section{Suggestions}

The paper provides significant impetus to the policy makers and environmentalist alike in terms of devising an ecological strategy. The researcher suggests the monitoring of the migration from rural to urban areas through provision of basic facilities in rural areas. On the other hand awareness campaigns and provision of basic facilities to the rural people (educational facilities, health facilities, food and empowerment in basic decision making) can reduce this problem.

The suggestions discussed below are duly endorsed by the three themes propounded by Vlahov and Galea (2002), as well as by Henderson (2006) who vehemently draws an anology of the ecological decay with the rapid popullation growth and its impact on the human health.

1) Government should check the migration from rural to urban by providing at least minimum basic requirements of life in the rural areas as education, health and drinking water facilities etc. Apart from devising a mechanism to determine the pace of rural-urban migration. As Cohen (2006) adds by propounding the general convergence of lifestyles between urban and rural areas; which the migration policy should accommodate.

2) Government should enforce the annual testing of exhaust emissions of motor vehicles efficiently to maintain the ecological rigor. This suggestion is in lieu to Antharvedi's (2007) discussion that by improving human settlement, creating environmental awareness in the citizens, implementation of integrated planning and management, we can improve the sustainability of the environment.

3) Government should introduce an Environmental Impact Fee for all private developers selecting to locate their residential or industrial development in environmentally sensitive areas.

4) Government should implement a domestic waste collection and treatment program within the cities to deal with high volumes of uncollected waste and to handle disposal of existing levels of collected waste. In this regard, a national sewerage and pollution control program should be established. This would provide urban centers with assistance to install sewerage/sanitation systems with treatment facilities. Cronin et al. (2004) as well as Bruce et al. (2000) vehemently brings to notice the negligence and compromise of the state towards the ground water. Therefore, the government should impose the realistic standards for the disposal of liquid waste throughout the country.

\section{References}

Antharvedi, Usha. (2007). Urban Environment - Sustainable Development. [Online] Available: http://ssrn.com/abstract $=955789$

Bengtson, V. L. (2001). Beyond the Nuclear Family: The Increasing Importance of Multigenerational Bonds. Journal of Marriage and Family. Wiley Online Library, University of Southern California, Vol. 63, No. 1, pp.1-16.

Brennan, E. M. (1999). Population, Urbanization, Environment, and Security: A Summary of the Issues. Environmental Change \& Security Project Report, Issue 5.

Bruce N., R. Perez-Padilla, and R. Albalak (2000). Indoor Air Pollution in Developing Countries: A Major Environmental and Public Health Challenge. Bulletin of the World Health Organization, 78(9): 1078-92.

Cohen, B. (2005). Urbanization in developing countries: Current trends, future projections, and key challenges for sustainability committee on Population. National Research Council, 500 Fifth Street, N.W., Washington, DC 20001, USA.

Cohen, B. (2006). Urbanization in developing countries: Current trends, future projections, and key challenges for sustainability. By Committee on Population, National Research Council, 500 Fifth Street, N.W., Washington, DC 20001,USA Journal, 28 pp. 63-80. 
Cronin, A. A., Breslin, N., Taylor, R. and Pedley, S. (2004). Assessing the risks to groundwater quality from on-site sanitation and poor sanitary well completion in Ecosan Closing the Loop. Proceedings of the 2nd International Conference on Ecological Sanitation, Lubeck, Germany.

Ellen Brennan. (1999). Popullation, Urbanization, Environment, and Security: A Summary of the Issues. Comparative Urban Studies: Occasional paper Series no. 22. Washington, DC: Woodrow Wilson International Center for Scholars, 1999, 12.

Geoforum, T. and Zoulani, A. (2007). Malaria and urbanization in central Africa: the example of Brazzaville. Part III: Relationships between urbanization and the intensity of malaria transmission, Health and environmental Organization of central Africa.

Henderson, J. V., Somik V. L., Hyoung G. W., Daniel D. M. and Deichmann, U. (2006). Um Exame dos Padrões de Crescimento das Cidades Brasileiras. Journal of Development Economics. Elsevier, Vol. 80, No. 2, pp. 350-388.

Lee C-M, Fujita M. (1997). Efficient configuration of a greenbelt: theoretical modeling of greenbelt amenity. Environment and Planning A, 29(11):1999-2017. http://dx.doi.org/10.1068/a291999

Lindh, G. (1983). Water and the city. Unesco, Paris. ISBN 92-3-102194-X.

Manzoor, M. M., Rabia, E. and Raghib, N. (2010). Socio-economic status and modern values with the impact of internal and international migration in a transitional economy of Pakistan. Population Association of Pakistan, Islamabad, Pakistan.

Martinez, R., Manning, G., Whyte D. B., T. Hunter, T. and Sudarsanam, S. (2002). The Protein Kinase Complement of the Human Genome. SUGEN Inc., 230 East Grand Avenue, South San Francisco, CA 94080, USA, 298, No. 5600, pp. 1912-1934.

Moorea, M., Philip G. and Barbara S. K. (2003). Global Urbanization and impacts on health. Journal of Hygiene and Environmental Health, Vol. 206, pp.269-278. http://dx.doi.org/10.1078/1438-4639-00223

Pakistan Education Cell. (2001). Curriculam Wing, Ministry of Education, Islamabad.

Pakistan Social and Living Standards Measurement Survey. (2010-11). [Online] Available: http://statpak.gov.pk/fbs/content/pakistan-social-and-living-standards-measurement-survey-pslm-2010-11-provin cial-district-0

Parkinson, J. and Tayler, K. (2003). Decentralized wastewater management in peri-urban areas in low-income countries. Journal of Environment and Urbanization, Vol. 15, No. 1, pp. 15-75 http://dx.doi.org/10.1177/095624780301500119

Taha, S. M. (2010). Policy Intervention for Managing Population Proliferation for Politically and Environmentally Sustainable Urban Development in Karachi. Journal of Population, Peace and Development, Tenth Annual Population Conference Proceedings in Islamabad, Pakistan.

Vlahov, David and Galea, Sandro. (2002). Urbanization, urbanicity and health. Academy of Medicine. New York: Oxford University Press.

World Bank. World Development Report. (1999/2000). Entering the $21^{\text {st }}$ Century. New York: Oxford University Press.

Table 1. Hypothesis No. 1: Rapid urbanization growth is the leading cause of ecological decay in the cities

\begin{tabular}{|l|l|l|}
\hline $\begin{array}{l}\text { Urbanization results in } \\
\text { Ecological decay }\end{array}$ & Frequency & Percentage \\
\hline Yes & 136 & 68 \\
\hline No & 64 & 32 \\
\hline Total & 200 & 100 \\
\hline
\end{tabular}




\begin{tabular}{|l|l|l|l|l|}
\hline Predictor & Coefficient & SECoef & Z & P \\
\hline Constant & 1.31 & 0.32 & 4.18 & 0 \\
\hline Urbanization & 0.76 & 0.36 & 2.12 & 0.034 \\
\hline
\end{tabular}

Likelihood Ratio Test

Log-Likelihood $=-122.964$

Test that all slopes are zero: $\mathrm{G}=4.819, \mathrm{DF}=1, \mathrm{P}$-Value $=0.034$

Table 2. Hypothesis No. 2: Rapid urbanization is the major determinant of increased nuclear family construction

\begin{tabular}{|l|l|l|}
\hline $\begin{array}{l}\text { Urbanization leads to } \\
\text { nuclear family system }\end{array}$ & Frequency & Percentage \\
\hline Yes & 132 & 66 \\
\hline No & 68 & 34 \\
\hline Total & 200 & 100 \\
\hline
\end{tabular}

\begin{tabular}{|l|l|l|l|l|}
\hline Predictor & Coefficient & SECoef & $Z$ & $P$ \\
\hline Constant & -1.30625 & 0.312660 & -4.18 & 0 \\
\hline Urbanization & 3.08964 & 0.395164 & 7.82 & 0 \\
\hline
\end{tabular}

Likelihood Ratio Test $\quad$ Log-Likelihood $=-88.863$

Test that all slopes are zero: $\mathrm{G}=78.688, \mathrm{DF}=1, \mathrm{P}$-Value $=0.000$

Table 3. Hypothesis No. 3: Urbanization results in poor sanitation facilities in the urban areas

\begin{tabular}{|l|l|l|}
\hline $\begin{array}{l}\text { Urbanization results in } \\
\text { poor sanitation facilities }\end{array}$ & Frequency & Percentage \\
\hline Yes & 132 & 66 \\
\hline No & 68 & 34 \\
\hline Total & 200 & 100 \\
\hline
\end{tabular}

\begin{tabular}{|l|l|l|l|l|}
\hline Predictor & Coefficient & SECoef & Z & P \\
\hline Constant & -2.04307 & 0.401716 & -5.09 & 0 \\
\hline Urbanization & 4.23233 & 0.490718 & 8.62 & 0 \\
\hline
\end{tabular}

Likelihood Ratio Test

Log-Likelihood $=-67.143$

Test that all slopes are zero: $\mathrm{G}=122.129, \mathrm{DF}=1, \mathrm{P}-$ Value $=0.000$ 
Table 4. Hypothesis No. 4: Urbanization affects the quality of drinking water

\begin{tabular}{|l|l|l|}
\hline $\begin{array}{l}\text { Urbanization affects the quality } \\
\text { of drinking water }\end{array}$ & Frequency & Percentage \\
\hline Yes & 120 & 60 \\
\hline No & 80 & 40 \\
\hline Total & 200 & 100 \\
\hline
\end{tabular}

\begin{tabular}{|l|l|l|l|l|}
\hline Predictor & Coefficient & SE Coef & $Z$ & $P$ \\
\hline Constant & -2.41591 & 0.466747 & -5.18 & 0 \\
\hline Urbanization & 3.98279 & 0.517895 & 7.69 & 0 \\
\hline
\end{tabular}

Likelihood Ratio Test Log-Likelihood $=-81.248$

Test that all slopes are zero: $\mathrm{G}=106.709, \mathrm{DF}=1, \mathrm{P}-$ Value $=0.000$

Table 5. Hypothesis No. 5: Higher urbanization leads towards increased air pollution in cities

\begin{tabular}{|l|l|l|}
\hline Urbanization results in air pollution & Frequency & Percentage \\
\hline Yes & 143 & 71.5 \\
\hline No & 57 & 28.5 \\
\hline Total & 200 & 100 \\
\hline
\end{tabular}

\begin{tabular}{|l|l|l|l|l|}
\hline Predictor & Coefficient & SECoef & Z & P \\
\hline Constant & -1.12059 & 0.297331 & -3.77 & 0 \\
\hline Urbanization & 3.57473 & 0.432582 & 8.26 & 0 \\
\hline
\end{tabular}

\section{Likelihood Ratio Test Log-Likelihood $=-72.480$}

Test that all slopes are zero: $\mathrm{G}=94.085, \mathrm{DF}=1, \mathrm{P}-$ Value $=0.000$ 